\title{
The Determinants of COVID-19 Vaccine Acceptance in Sumatra
}

\author{
Cindy Sidarta1, Andree Kurniawan2", Nata P H Lugito2, Jeremia Imanuel Siregar², Veli Sungono ${ }^{3}$, Rivaldo Steven \\ Heriyanto $^{4}$, Novia Lauren Sieto ${ }^{1}$, Devina Adella Halim ${ }^{4}$, Claudia Jodhinata ${ }^{4}$, Saraswati Anindita Rizki ${ }^{4}$, Terry \\ Devita Sinaga ${ }^{4}$, Chintya Marcella ${ }^{4}$, Felix Wijovi ${ }^{4}$, Billy Susanto ${ }^{4}$, Elizabeth Marcella ${ }^{4}$, Johan Wibowo ${ }^{4}$, Jonathan \\ Juniard Anurantha ${ }^{4}$, Michelle Imanuelly ${ }^{4}$, Michelle Indrawan ${ }^{4}$, Nadia Khoirunnisa Heryadi ${ }^{4}$
}

${ }^{1}$ Department of Medical Education, Faculty of Medicine, Pelita Harapan University, Tangerang, Indonesia, ${ }^{2}$ Department of Internal Medicine, Faculty of Medicine, Pelita Harapan University, Tangerang, Indonesia, ${ }^{3}$ Department of Public Health, Faculty of Medicine, Pelita Harapan University, Tangerang, Indonesia, ${ }^{4}$ Department of Medicine, Faculty of Medicine, Pelita Harapan University, Tangerang, Indonesia

\begin{abstract}
In light of the current coronavirus disease 2019 (COVID-19) vaccination programs being implemented worldwide, this study aimed to evaluate the COVID-19 vaccine acceptance survey in Indonesia conducted by the World Health Organization (WHO), the Ministry of Health of the Republic of Indonesia, the National Immunization Technical Advisory Group (NITAG), and the United Nations Children's Fund (UNICEF), published in November 2020. It was found that Sumatra Island having lower COVID-19 vaccine acceptance rates, with Aceh Province displaying the lowest level of vaccine acceptance. Thus, a cross-sectional study was conducted, and a logistic regression analysis was used to identify the factors affecting COVID-19 vaccine acceptance. Out of 368 respondents who participated in the survey, $143(38.9 \%)$ accepted the vaccine, and $225(61.1 \%)$ refused it. Vaccine safety concerns constituted the most reported reason for refusal $(43.6 \%)$. This study also found that province of residence and basic immunization status were determinants of COVID-19 vaccine acceptance in Sumatra. Concerns regarding vaccine safety might be the reason for the low level of vaccination in Sumatra. Increased education and encouragement from healthcare professionals and regional authority figures can alleviate public concerns and improve vaccine acceptance.
\end{abstract}

Keywords: COVID-19, determinants, vaccine

\section{Introduction}

The coronavirus disease 2019 (COVID-19) pandemic has impacted the lives of millions of people worldwide. In Indonesia, a cumulative total of 1,460,184 confirmed cases and 39,550 deaths have been reported to date. ${ }^{1}$ As the number of COVID-19 cases continues to increase; nations have rapidly developed vaccines to be made readily available for health workers and the general population. Vaccination programs have been implemented globally to relieve the socioeconomic burden on the healthcare system. The Indonesian Government has taken numerous measures towards implementing of a COVID-19 vaccination program. On January 11, 2021, the National Agency of Drug and Food Control/Badan Pengawas Obat dan Makanan (BPOM) published an Emergency Use Authorization (EUA) for the COVID-19 vaccine CoronaVac developed by Sinovac Biotech. ${ }^{2}$ On January 13, 2021, the President of the Republic of Indonesia, Joko Widodo, was the first Indonesian citizen to be vaccinated at the presidential palace, officially launching the COVID-19 vaccination program in
Indonesia. ${ }^{3}$ However, for the program to be successful, it is imperative to evaluate the public's perception and acceptance of the vaccine.

Several studies have explored the prevalence of COVID-19 vaccine acceptance and its determinants among various populations in different countries. The World Health Organization (WHO), together with the Indonesian Ministry of Health, the Indonesia Technical Advisory Group on Immunization (ITAGI), and the United Nations Children's Fund (UNICEF), made a comprehensive report on COVID-19 vaccine acceptance in Indonesia in 2020 . The survey revealed that $65 \%$ of respondents were willing to accept the vaccine, $8 \%$ refused, and the remaining respondents expressed hesitancy. ${ }^{4}$ However, this study did not elaborate on the factors that might have resulted in vaccine acceptance in each province. The survey was a descriptive study, while this study conducted an association analysis of the determinants specifically regarding the Sumatran population. Vaccine hesitancy, a delay in acceptance or refusal of vaccination regardless of its availability, is a

Correspondence*: Andree Kurniawan, Department of Internal Medicine, Pelita Harapan University, Karawaci, Tangerang, Banten, Indonesia 15811, E-mail: 
barrier to achieving herd immunity. ${ }^{5}$ The study reported that provinces in Sumatra were amongst those with lower COVID-19 vaccine acceptance rates, with Aceh having the lowest acceptance rate. ${ }^{4}$ Previous studies also reported that the provinces in Sumatra had incomplete immunization coverage rates of more than $70 \%$ in eight of ten provinces. ${ }^{6-8}$

The survey also demonstrated that vaccine acceptance varied based on geographical regions and socioeconomic factors such as economic status, religious and cultural beliefs, gender, insurance availability, and several concerns regarding the vaccine. ${ }^{4}$ Sociodemographic factors such as age, province, gender, and marital status were included as variables to stratify demographic factors on COVID-19 vaccine acceptance. Immunization status, religion, economic status, education, employment, healthcare worker status, and insurance ownership have been found to affect vaccine acceptance rates by previous studies. ${ }^{4}$ Incomplete immunization status often reflects limited knowledge and awareness regarding immunization, impacting vaccine acceptance. ${ }^{9}$ Religion was included as a variable due to concerns about whether the COVID-19 vaccine is considered halal (permissible), which may impact vaccine acceptance in the Indonesian population. Lower economic status, education, and unemployment have been correlated with lower vaccine acceptance rates. ${ }^{10-12}$ Healthcare workers may have more comprehensive knowledge of COVID-19 and relatively high awareness of the importance of vaccination and may be more willing to accept the vaccine. ${ }^{13-15}$ Insurance ownership, prior experience with COVID-19, knowledge of COVID-19 vaccine distribution by the government, and willingness to pay are also variables that could potentially impact vaccine acceptance.

Evaluating the various factors contributing to vaccine acceptance and hesitancy in each geographical location is essential. These were important because vaccine hesitancy is complicated and context-specific. ${ }^{16}$ This study was conducted to evaluate the determinants of COVID-19 vaccine acceptance in Sumatra. The second aim of the study was to understand the underlying issues present and develop strategies to overcome them.

\section{Method}

A cross-sectional online survey was designed using Google Forms and distributed through WhatsApp, Line, and Instagram between January and February 2021. Study samples were collected from ten provinces in Sumatra using a purposive sampling strategy. Inclusion criteria were respondents who consented to participate and were older than ten years of age. Respondents who did not complete the questionnaire were excluded. A previous study showed that $67 \%$ of respondents demonstrated acceptance of a potential COVID-19 vaccine. ${ }^{15}$

$$
n=\frac{Z \alpha^{2}(p q)}{d^{2}}=339 \approx 350
$$

Formula 1. Sample Size Estimation

Sample size was calculated using the formula as in Formula 1, where $\mathrm{n}$ is sample size, $\mathrm{p}=$ proportion, $\alpha=$ 0.05, $\mathrm{Z} \alpha=1.96$, and $d=0.05$.

After accounting for incomplete questionnaires and dropouts, the final optimal sample size was estimated to be 350 completed questionnaires. The questionnaire used in this study was a modified version of the WHO COVID-19 Vaccine Acceptance Survey in Indonesia questionnaire. ${ }^{4}$ The possible responses for "occupation" were modified to "unemployed non-healthcare worker," "employed non-healthcare worker," and "healthcare worker," which would be grouped into employment (employed/unemployed). Healthcare workers grouped into healthcare worker/non-healthcare worker status during data analysis. As previous studies have demonstrated the positive impact of prior immunization on future vaccine acceptance, an additional question regarding previous immunization history was added to the questionnaire. ${ }^{17-22}$

Ten provinces in Sumatra were grouped into high and low immunization coverage categories based on WHO statements that a vaccine coverage of $\geq 80 \%$ is considered high. ${ }^{23}$ Data from UNICEF's Sustainable Development Goals (SDG) Baseline Report on Children in Indonesia on immunization coverage of the third dose of diphtheria, pertussis, and tetanus (DPT3) vaccine was used. ${ }^{24}$ Data on DPT3 rather than measles vaccine coverage was used because the national immunization coverage for DPT3 was lower and better reflected the immunization coverage in Sumatra. Provinces with low immunization coverage included Aceh, Jambi, North Sumatra, Riau, South Sumatra, and West Sumatra. Those with high immunization coverage included Bangka Belitung Islands, Bengkulu, Lampung, and Riau Islands. Religion was reported as either Muslim or non-Muslim because the majority of the population of Sumatra is Muslim. ${ }^{25}$ Economic status was categorized as poor/ aspiring middle-class and middle/upper class based on an average household monthly expense cutoff of IDR $4,800,000$ (equivalent to US\$328.23. according to the April 12, 2021 exchange rate). ${ }^{26}$ Education was grouped into tertiary education and elementary and secondary education based on The Indonesian Law no. 20 of 2003 Concerning the National Education System. ${ }^{27}$

The data were analyzed using descriptive statistics. First, a cross-tabulation analysis was performed to evaluate the participants' response to vaccine acceptance 
Table 1. Sociodemographic Characteristics

\begin{tabular}{|c|c|c|c|}
\hline Variable & Category & $\mathbf{n}$ & $\%$ \\
\hline \multirow[t]{2}{*}{ Age } & $<25$ years & 121 & 32.9 \\
\hline & $\geq 25$ years & 247 & 67.1 \\
\hline \multirow[t]{4}{*}{ Province } & Provinces with low immunization coverage & & \\
\hline & (Aceh, Jambi, North Sumatra, Riau, South Sumatra, West Sumatra) & 244 & 66.3 \\
\hline & Provinces with high immunization coverage & & \\
\hline & (Bangka Belitung Islands, Bengkulu, Lampung, Riau Islands) & 124 & 33.7 \\
\hline \multirow{2}{*}{ Gender } & Females & 135 & 36.7 \\
\hline & Males & 233 & 63.3 \\
\hline \multirow{2}{*}{ Marital status } & Unmarried (single, divorced, or widowed) & 166 & 45.1 \\
\hline & Married & 202 & 54.9 \\
\hline \multirow[t]{2}{*}{ Basic immunization } & Incomplete & 131 & 35.6 \\
\hline & Complete & 237 & 64.4 \\
\hline \multirow[t]{2}{*}{ Religion } & Non-Muslim & 134 & 36.4 \\
\hline & Muslim & 234 & 63.6 \\
\hline \multirow[t]{2}{*}{ Economic status } & Poor/aspiring middle-class & 283 & 76.9 \\
\hline & Middle/upper class & 85 & 23.1 \\
\hline \multirow{2}{*}{ Education } & Elementary and secondary education & 208 & 56.5 \\
\hline & Tertiary Education & 160 & 43.5 \\
\hline \multirow[t]{2}{*}{ Employment } & Unemployed & 14 & 3.8 \\
\hline & Employed & 354 & 96.2 \\
\hline \multirow[t]{2}{*}{ Healthcare worker } & Non-healthcare worker & 334 & 90.8 \\
\hline & Healthcare worker & 34 & 9.2 \\
\hline \multirow[t]{2}{*}{ Insurance ownership } & No Insurance & 33 & 9 \\
\hline & Owns insurance & 335 & 91 \\
\hline \multirow{2}{*}{$\begin{array}{l}\text { Experience with COVID-19: Have you } \\
\text { ever been infected with COVID-19, } \\
\text { or do you know someone close to you } \\
\text { who has been infected with COVID-19? }\end{array}$} & No/not sure & 281 & 76.4 \\
\hline & Yes & 87 & 23.6 \\
\hline \multirow{2}{*}{$\begin{array}{l}\text { Do you know that the Government of } \\
\text { the Republic of Indonesia has planned } \\
\text { to provide the COVID-19 vaccine? }\end{array}$} & No & 37 & 10.1 \\
\hline & Yes & 331 & 89.9 \\
\hline Willingness to pay: Are you willing to pay & Not willing/not sure & 247 & 67.1 \\
\hline for the COVID-19 vaccine? & Willing & 121 & 32.9 \\
\hline
\end{tabular}

concerning each independent variable. A bivariate analysis evaluated the associations between each independent variable and vaccine acceptance separately. Then, independent variables with a p-value $\leq 0.25$ and independent variables theoretically associated with vaccine acceptance were included in the multivariate analysis. For the multivariate analysis, the model was analyzed for confounding variables and potential interactions between the independent variables. The final logistic regression model was used to identify COVID-19 vaccine acceptance determinants in Sumatra. All data analyses were performed using SPSS software (IBM Corp., released 2020, IBM SPSS Statistics for Macintosh, version 27.0, Armonk, NY).

\section{Results}

A total of 368 respondents provided consent and completed the survey (Table 1$)$. The majority $(67.1 \%)$ of respondents were 25 years or older, and $66.3 \%$ were from provinces with low immunization coverage. More male respondents than female ones; $54.9 \%$ were married, and $64.4 \%$ received complete basic immunization. For the rest of the sociodemographic variables,
Table 2. Reasons for Vaccine Refusal

\begin{tabular}{lcc}
\hline Reasons & (n = 225) & $\%$ \\
\hline Concerns about the vaccine's safety & 98 & 43.6 \\
Concerns about the vaccine side effects & 57 & 25.3 \\
Concerns about the vaccine's efficacy & 36 & 16.0 \\
Other unspecified reason & 11 & 4.9 \\
Lack of trust & 9 & 4.0 \\
Unsure if a family will accept the vaccine & 5 & 2.2 \\
Religious beliefs & 4 & 1.8 \\
Comorbidities & 3 & 1.3 \\
Lack of knowledge of the vaccine & 2 & 0.9 \\
\hline
\end{tabular}

$63.6 \%$ were Muslim, $76.9 \%$ belonged to the poor/aspiring middle-class category, $43.5 \%$ received tertiary education, $96.2 \%$ were employed, $90.8 \%$ were non-healthcare workers, and 91\% owned health insurance. Concerns regarding vaccine safety constituted the most reported reason for refusal $(43.6 \%)$, followed by side effects and efficacy (Table 2 ).

Cross-tabulation and bivariate analysis was done between the independent variables and vaccine acceptance (Table 3). Out of 368 respondents, 143 $(38.9 \%)$ respondents answered "yes" to receiving the 
Table 3. Cross-tabulation and Bivariate Analysis

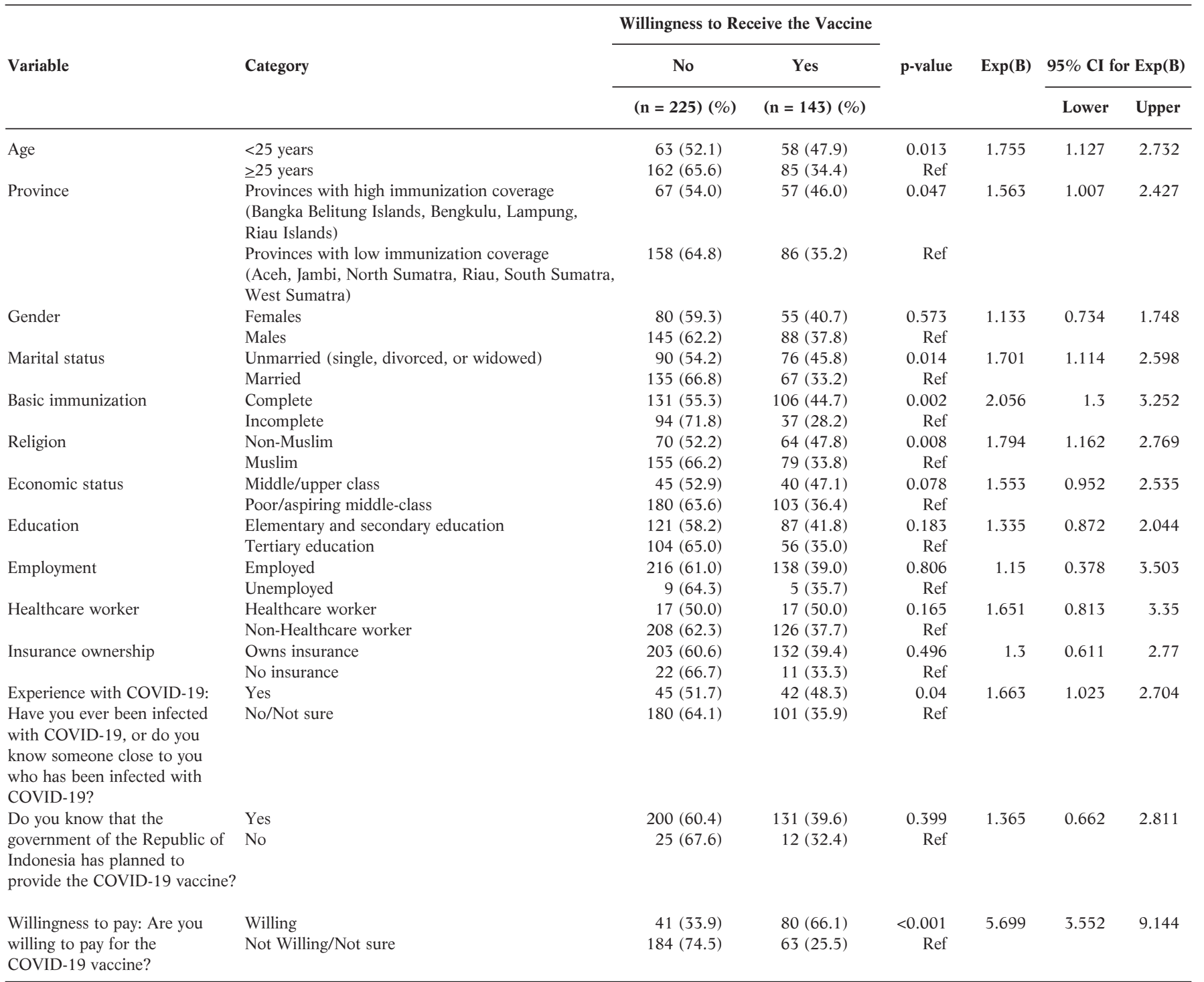

Note: $\mathrm{CI}=$ Confidence Interval

vaccine, and the remaining $225(61.1 \%)$ respondents answered "no." The variables that demonstrated significant associations with vaccine acceptance were age, province, marital status, basic immunization, religion, willingness to pay, and experience with COVID19 (p-value<0.05).

In the logistic regression analysis (Table 4), the authors included all variables from the bivariate analysis that were statistically significant ( $p$-value $<0.25$ ), including age, province, marital status, basic immunization, religion, economic status, education, healthcare worker, willingness to pay, and experience with COVID-19. However, several studies on factors affecting vaccine acceptance have consistently shown that employment status is associated with vaccine acceptance; 28,29 therefore, employment status was added to the multivariate analysis. The authors removed all variables with a p-value $>0.05$ and did not alter other variables' odds ratio (OR) by more than $10 \%$. Variables that were removed included employment status, marital status, healthcare worker, and experience with COVID-19. Confounding variables included age, religion, economic status, and education-willingness to pay significantly associated with age, province, and religion ( $\mathrm{p}$ value $<0.05$ ). Seven variables were associated with vaccine acceptance: age, province, basic immunization, 
Table 4. Logistic Regression Analysis of Determinants of COVID-19 Vaccine Acceptance, Final Model

\begin{tabular}{|c|c|c|c|c|c|}
\hline \multirow{2}{*}{ Variable } & \multirow{2}{*}{$\beta$} & \multirow{2}{*}{ Sig. (p-value) } & \multirow{2}{*}{$\operatorname{Exp}(B)$} & \multicolumn{2}{|c|}{ 95\% CI for $\operatorname{Exp}(B)$} \\
\hline & & & & Lower & Upper \\
\hline Age $(<25$ years old $)$ & -0.505 & 0.271 & 0.603 & 0.246 & 1.483 \\
\hline Province (High immunization coverage) & 1.001 & 0.002 & 2.721 & 1.453 & 5.096 \\
\hline Basic immunization (Complete) & 0.709 & 0.009 & 2.031 & 1.194 & 3.455 \\
\hline Religion (Muslim) & -0.745 & 0.114 & 0.475 & 0.189 & 1.196 \\
\hline Economic status (Poor/aspiring middle-class) & 0.338 & 0.289 & 1.402 & 0.751 & 2.615 \\
\hline Education (Elementary and secondary education) & 0.135 & 0.612 & 1.144 & 0.68 & 1.924 \\
\hline Willingness to pay (Willing) & 0.691 & 0.26 & 1.995 & 0.599 & 6.639 \\
\hline Willingness to pay (Willing) by Age ( $<25$ years old) & 1.683 & 0.011 & 5.38 & 1.467 & 19.722 \\
\hline Willingness to pay (Willing) by Province (High immunization coverage) & -1.333 & 0.022 & 0.264 & 0.084 & 0.828 \\
\hline Willingness to pay (Willing) by Religion (Muslim) & 1.954 & 0.006 & 7.058 & 1.755 & 28.381 \\
\hline
\end{tabular}

Note: $\mathrm{CI}=$ Confidence Interval

religion, economic status, education, and willingness to pay. Province and basic immunization were significant determinants of COVID-19 vaccine acceptance ( $p$ value $<0.05)$. Respondents from provinces with high immunization coverage were 2.721 times more likely to accept COVID-19 vaccination than provinces with low immunization coverage $(\mathrm{OR}=2.721 ; 95 \%$ confidence interval $[\mathrm{CI}]=1.453-5.096 ; \mathrm{p}$-value $=0.002)$. Respondents with completed immunization history were 2.031 times more likely to accept COVID-19 vaccination compared to those with incomplete immunization history $(\mathrm{OR}=2.031 ; 95 \% \mathrm{CI}=1.194-3.455 ; \mathrm{p}$-value $=0.009)$.

\section{Discussion}

Vaccination programs were developed as part of a global effort to achieve herd immunity. However, a certain threshold of vaccination must be achieved for success. Studies on COVID-19 vaccine acceptance have been conducted in various countries and population groups worldwide to identify existing barriers and develop evidence-based interventions to overcome them. This study evaluated the determinants of COVID-19 vaccine acceptance in Sumatra only. Overall, there was a low rate of COVID-19 vaccine acceptance in Sumatra, with only $38.9 \%$ of respondents being willing to accept the vaccine. This finding agreed with the WHO COVID-19 Vaccine Acceptance Survey results in Indonesia, showing that provinces in Sumatra had low vaccine acceptance rates. ${ }^{4}$ Differences in acceptance rates between this study and the WHO survey may be due to the progression of the COVID-19 vaccination program concerning the time of data collection and difference in sample size. Previous studies on vaccine acceptance and immunization coverage in Sumatra have also demonstrated similar findings. ${ }^{30-33}$ In this study, the province of residence and basic immunization status were significantly associated with COVID-19 vaccine acceptance.
The age was not associated to the vaccine acceptance. Previous systematic review found that sex was the demographic variables examined most frequently across the ten studies and there was no consistent association between these variables. ${ }^{21}$ Education was also not associated to the vaccine acceptance. This was stated from previous study that there were no differences between developing and developed countries in term of vaccine acceptance. ${ }^{19}$

Vaccine acceptance was 2.721 times more likely in provinces with high immunization coverage than provinces with low immunization coverage $(\mathrm{OR}=2.721$; $95 \% \mathrm{CI}=1.453-5.096$; $\mathrm{p}$-value $=0.002$ ). A possible reason for this is the presence of religious norms and beliefs in areas with low immunization coverage. 34,35 The majority of the population in Sumatra is Muslim, and the Islamic Shari'ah law may affect public acceptance towards vaccination due to its conservativism. In the past, vaccine acceptance has been a challenge due to fear that vaccines may contain animal-derived products, considered haram (forbidden) in Islamic law. ${ }^{35,36}$ In 2001, the WHO issued a statement based on Islamic religious scholars' opinions that animal-derived products that have been transformed are considered halal for medical use. ${ }^{35,36}$ The COVID-19 pandemic presents a similar situation in that concerns about the vaccine's halal status have impacted vaccine acceptance in the Indonesian population. For reassurance, the Indonesian Ulama Council/Majelis Ulama Indonesia (MUI) released a fatwa (pronouncement) declaring that the COVID-19 vaccine is halal for use. ${ }^{37}$

Respondents with complete immunization history were 2.031 times more likely to accept the vaccine than those with incomplete immunization $(\mathrm{OR}=2.031 ; 95 \%$ $\mathrm{CI}=1.194-3.455 ; \mathrm{p}$-value $=0.009)$. Previous studies have consistently proven the positive impact of prior vaccination on future vaccine acceptance. ${ }^{19,22,38} \mathrm{~A}$ study in China reported that past influenza vaccination increased 
COVID-19 vaccine acceptance by $1.43-2.51$-fold. ${ }^{22} \mathrm{~A}$ systematic review also reported that previous vaccination history had the most significant effect on accepting of a newly released vaccine during a pandemic. 22 Out of seven studies that evaluated previous vaccination and future vaccine acceptance, six reported ORs ranging from 1.27 to 5.03 . Two studies reported that prior vaccination was one of the top three determinants of vaccine acceptance. ${ }^{19,22,38}$

Most respondents cited concerns on vaccine safety, side effects, and efficacy. The vaccination of the President of the Republic of Indonesia was broadcast on television to increase the public's trust in the vaccine. In Indonesia, the COVID-19 vaccine was distributed in four phases. This study conducted surveys from January to February 2021, during which the vaccination program in Indonesia had only just begun, and healthcare workers were the first to receive the vaccine. Because only healthcare workers had been vaccinated, the public may still have had uncertainties regarding the vaccine's safety. Additionally, constant media coverage may have increased salience among the public regarding the vaccine. This situation, along with a lack of knowledge and information, ${ }^{39}$, may have hindered vaccine acceptance.

The result of this study can aid the government and healthcare systems in implementing effective vaccination strategies to improve vaccine acceptance in Sumatra. Sumatra's low vaccine acceptance rate is partly caused by conservatism and a history of vaccine refusal, as shown by incomplete immunization history. Therefore, measures should be taken to increase education and communicate vaccination to the general public in understandable, layperson's terms, especially regarding vaccine safety. Together with other sectors such as religious or political authority figures, the Ministry of Health should reach out to all population groups and educate them on the importance of vaccination. Lack of knowledge and understanding, together with misinformation and salience, results in a lack of confidence, uncertainty, and fear of the vaccine. Increasing public health education on the mechanics and benefits of vaccination may improve not only COVID-19 vaccination rates but overall immunization rates in the province of Sumatra. Implementing these measures will be one step closer to ensuring the public's confidence in the vaccine and improving vaccine acceptance rates.

This study is among the first to evaluate determinants of COVID-19 vaccine acceptance on an island of Indonesia. It could provide reliable data on participants' responses as this study used a questionnaire similar to the survey conducted by the WHO, the Indonesian Ministry of Health, NITAG, and UNICEF. This study also had no missing data, and the collected sample was fairly representative of the population of Sumatra. Most im- portantly, this could stratify data based on sociodemographic parameters and provincial regions to predict COVID-19 vaccine acceptance in Sumatra. This understanding of the current barriers to vaccine acceptance may help identify population groups that require further attention and develop effective immunization strategies within the COVID-19 vaccination program.

This study has several limitations. Because the study was cross-sectional, the results reflect respondents' attitudes at the time of data collection only. Respondents' attitudes may change over time. The authors also did not evaluate other factors such as risk perception and trust in the health system. ${ }^{29,30,40}$ The sample only included 34 health workers, potentially producing biased results on whether health worker status affected vaccine acceptance. The sampling technique may also have led to selection bias. Respondents required a smartphone or computer and internet access to participate. Generalizability sample due to the exclusion of lower socioeconomic classes, those with a lack of access to technology, and illiterate individuals.

\section{Conclusion and Recommendation}

This study found that province with high communization coverage, previous complete basic immunization, and willingness to pay of vaccine were the determinants of vaccine acceptance in Sumatra region. Increasing public health education by healthcare workers and authority figures is a viable strategy to improve vaccine acceptance. Alleviating public concerns about the vaccine is one of strategy to increase vaccine acceptance.

\begin{abstract}
Abbreviations
COVID-19: coronavirus disease 2019; WHO: World Health Organization; ITAGI: Indonesia Technical Advisory Group on Immunization; UNICEF: The United Nations Children's Fund; BPOM: Badan Pengawas Obat dan Makanan; EUA: Emergency Use Authorization; SDG: Sustainable Development Goals; DPT3: Third Dose of Diphtheria, Pertussis, and Tetanus; CI: Confidence Interval; OR: Odds Ratio; MUI: Majelis Ulama Indonesia.
\end{abstract}

Ethics Approval and Consent to Participate

Ethics approval was obtained from the Faculty of Medicine, Pelita Harapan University's Research Ethics Committee, approval number 085/K- LKJ/ETIK/II/2021.

\section{Competing Interest}

The authors declare that there are no significant competing financial, professional, or personal interests that might have affected the performance.

\section{Availability of Data and Materials}

The data are not publicly available as it contains information that could compromise the privacy of research participants. 


\section{Authors' Contribution}

CS conceptualized the study, outlined the design, analyzed the data, and wrote the manuscript. AK, NPHL, and JIS validated the study, supervised and revised the final manuscript. VS provided statistical advice, supervised and revised the final manuscript. NLS, SAR, TDS, CM assisted in data collection, RSH, DAH, CJ, FW, BS, EM, JW, JJA, MI, MI, NKH assisted in research proposal development and data collection.

\section{Acknowledgment \\ Not Applicable}

\section{References}

1. Satuan Tugas Penanganan COVID-19. Peta sebaran COVID-19; 2021.

2. The Jakarta Globe. Indonesia approves sinovac vaccine amid dramatic surge in coronavirus cases. The Jakarta Globe; 2021.

3. Widianto S. Indonesia launches vaccination drive as COVID-19 deaths hit record. Reuters; 2021.

4. World Health Organization. COVID-19 Vaccine acceptance survey in Indonesia; 2020.

5. MacDonald NE, Eskola J, Liang X, Chaudhuri M, Dube E, Gellin B, et al. Vaccine hesitancy: definition, scope and determinants. 2015; 33 (34): 4161-4.

6. Hardhantyo M, Chuang YC. Urban-rural differences in factors associated with incomplete basic immunization among children in Indonesia: a nationwide multilevel study. Pediatr Neonatol. 2020; 62 (1): 80-9.

7. Pronyk P, Sugihantono A, Sitohang V, Moran T, Kadandale S, Muller S, et al. Vaccine hesitancy in Indonesia. Lancet Planet Heal. 2019; 3 (3): e114-5.

8. United Nations International Children's Emergency Fund. Roadmap of SDGs Indonesia: a highlight; 2019.

9. Dubé E, Vivion M, MacDonald NE. Vaccine hesitancy, vaccine refusal and the anti-vaccine movement: influence, impact and implications. Expert Rev Vaccines. 2014; 14 (1): 99-117.

10. Yufika A, Wagner AL, Nawawi Y, Wahyuniati N, Anwar S, Yusri F, et al. Parents' hesitancy towards vaccination in Indonesia: a crosssectional study in Indonesia. Vaccine. 2020; 38 (11): 2592-9.

11. Esposito S, Principi N, Cornaglia G. Barriers to the vaccination of children and adolescents and possible solutions. Clin Microb Infect. 2014; (20): 25-31.

12. Azizi FSM, Kew Y, Moy FM. Vaccine hesitancy among parents in a multi-ethnic country, Malaysia. Vaccine. 2017; 35: 2955-61.

13. Vasilevska M, Ku J, Fisman DN. Factors associated with healthcare worker acceptance of vaccination: a systematic review and metaanalysis. Infect Control Hosp Epidemiol. 2014; 35: 699-708.

14. Nguyen TTM, Lafond KE, Nguyen TX, Tran PD, Nguyen HM, Ha VTC, et al. Acceptability of seasonal influenza vaccines among health care workers in Vietnam in 2017. Vaccine. 2020; 38: 2045-50.

15. Harapan H, Wagner AL, Yufika A, Winardi W, Anwar S, Gan AK, et al. Acceptance of a COVID-19 Vaccine in Southeast Asia: a crosssectional study in Indonesia. Front Public Heal. 2020; 8: 1-8.

16. Kashte S, Gulbake A, El-Amin SF, Gupta A. COVID-19 vaccines: rapid development, implications, challenges and future prospects. Hum Cell; 2021.

17. Raude J, Caille-Brillet A-L, Setbon M. The 2009 pandemic H1N1 influenza vaccination in France: who accepted to receive the vaccine and why? PLoS Currents. 2010; 2.

18. Lau JTF, Yeung NCY, Choi KC, Cheng MYM, Tsui HY, Griffiths S. Factors in association with acceptability of A/H1N1 vaccination during the influenza A/H1N1 pandemic phase in the Hong Kong general population. Vaccine. 2010; 28 (29).

19. Eastwood K, Durrheim DN, Jones A, Butler M. Acceptance of pandemic (H1N1) 2009 influenza vaccination by the Australian public. Medical Journal of Australia. 2010; 192 (1).

20. Schwarzinger M, Flicoteaux R, Cortarenoda S, Obadia Y, Moatti J-P. Low acceptability of A/H1N1 pandemic vaccination in French adult population: did public health policy fuel public dissonance? PLoS ONE. 2010; 5 (4).

21. Wilson K, Nguyen, Holdt Henningsen, Brehaut, Hoe. Acceptance of a pandemic influenza vaccine: a systematic review of surveys of the general public. Infection and Drug Resistance. 2011; 4 (1): 197-207.

22. Wang J, Jing R, Lai X, Zhang H, Lyu Y, Knoll MD, et al. Acceptance of COVID-19 vaccination during the COVID-19 pandemic in China. Vaccines. 2020; 8 (3).

23. World Health Organization. Increasing immunization coverage at the health facility level. Geneva; 2002.

24. United Nations International Children's Emergency Fund. SDG baseline report on children in Indonesia; 2017.

25. Statistics Indonesia (Badan Pusat Statistik). Penduduk menurut wilayah dan agama yang dianut; 2010.

26. World Bank. Aspiring Indonesia: expanding the middle class; 2019

27. Undang-Undang Republik Indonesia nomor 20 tahun 2003 tentang sistem pendidikan nasional. Republik Indonesia. 2003 p. 159-70.

28. Lazarus J V, Ratzan SC, Palayew A, Gostin LO, Larson HJ, Rabin K, et al. A global survey of potential acceptance of a COVID-19 vaccine. Nat Med. 2021; 27 (2): 225-8.

29. Malik AA, McFadden SAM, Elharake J, Omer SB. Determinants of COVID-19 vaccine acceptance in the U.S. EClinicalMedicine. 2020; 26: 100495.

30. Yufika A, Wagner AL, Nawawi Y, Wahyuniati N, Anwar S, Yusri F, et al. Parents' hesitancy towards vaccination in Indonesia: a crosssectional study in Indonesia. Vaccine. 2020; 38 (11): 2592-9.

31. Harapan H, Anwar S, Dimiati H, Hayati Z, Mudatsir M. Diphtheria outbreak in Indonesia, 2017: an outbreak of an ancient and vaccinepreventable disease in the third millennium. Clin Epidemiol Glob Heal. 2019; 7 (2): 261-2.

32. Harapan H, Anwar S, Bustaman A, Radiansyah A, Angraini P, Fasli R, et al. Modifiable determinants of attitude towards dengue vaccination among healthy inhabitants of Aceh, Indonesia: findings from a community-based survey. Asian Pac J Trop Med. 2016; 9(11): 111522.

33. Herliana P, Douiri A. Determinants of immunisation coverage of children aged 12-59 months in Indonesia: a cross-sectional study. BMJ Open. 2017; 7 (12): 1-14.

34. Harapan H, Shields N, Kachoria AG, Shotwell A, Wagner AL. Religion and measles vaccination in Indonesia, 1991-2017. Am J Prev 
Med. 2021; 60 (1): S44-52.

35. Padmawati RS, Heywood A, Sitaresmi MN, Atthobari J, MacIntyre CR, Soenarto Y, et al. Religious and community leaders' acceptance of rotavirus vaccine introduction in Yogyakarta, Indonesia: a qualitative study. BMC Public Health. 2019; 19 (1): 1-6.

36. States M, Strategic WHO, Group A, Who A, Le E. Rotavirus vaccines WHO position paper: January 2013 - recommendations. Vaccine. 2013; 31 (52): 6170-1.

37. Majelis Ulama Indonesia. Fatwa Majelis Ulama Indonesia nomor : 02 tahun 2021 tentang produk vaksin covid-19 dari sinovac life sciences co. Ltd. China dan PT. Bio Farma. 2021 p. 1-8.

38. Seale H, Heywood AE, McLaws ML, Ward KF, Lowbridge CP, Van $\mathrm{D}$, et al. Why do I need it? I am not at risk! Public perceptions towards the pandemic (H1N1) 2009 vaccine. BMC Infect Dis. 2010; 10.

39. Adella Halim D, Kurniawan A, Agung FH, Angelina S, Jodhinata C, Winata S, et al. Understanding of young people about COVID-19 during early outbreak in Indonesia. Asia-Pacific J Public Heal. 2020; 32 (6-7): 363-5.

40. Rizki SA, Kurniawan J, Budimulia P, Sylvanus P, Alexandra A, Sinaga $\mathrm{TD}$, et al. Knowledge, attitude, and practice in Indonesia health care workers regarding COVID-19. Asia Pacific J Public Heal. 2021; 33 